\title{
Kefir-isolated bacteria and yeasts inhibit Shigella flexneri invasion and modulate pro- inflammatory response on intestinal epithelial cells
}

\author{
P.A. Bolla ${ }^{1,2}$, A.G. Abraham ${ }^{3,4}$, P.F. Pérez ${ }^{1,3}$ and M. de los Angeles Serradell ${ }^{1 *}$ \\ ${ }^{1}$ Cátedra de Microbiología, Departamento de Ciencias Biológicas, Facultad de Ciencias Exactas, Universidad Nacional \\ de La Plata, 47 y 115, La Plata, CP 1900, Argentina; ${ }^{2}$ División Química Analítica, Departamento de Química, Facultad \\ de Ciencias Exactas, Universidad Nacional de La Plata, 47 y 115, La Plata, CP 1900, Argentina; ${ }^{3}$ Centro de Investigación \\ y Desarrollo en Criotecnología de Alimentos (CIDCA), CCT-La Plata, CONICET, 47 y 116, La Plata, CP 1900, Argentina; \\ ${ }^{4}$ Área de Bromatología y Control de Alimentos, Departamento de Ciencias Biológicas, Facultad de Ciencias Exactas, \\ Universidad Nacional de La Plata, 47 y 115, La Plata, CP 1900, Argentina; maserr@biol.unlp.edu.ar
}

Received: 8 May 2015 / Accepted: 20 August 2015

(c) 2015 Wageningen Academic Publishers

RESEARCH ARTICLE

\begin{abstract}
The aim of this work was to evaluate the ability of a kefir-isolated microbial mixture containing three bacterial and two yeast strains (MM) to protect intestinal epithelial cells against Shigella flexneri invasion, as well as to analyse the effect on pro-inflammatory response elicited by this pathogen. A significant decrease in S. flexneri strain 72 invasion was observed on both HT-29 and Caco-2 cells pre-incubated with MM. Pre-incubation with the individual strains Saccharomyces cerevisiae CIDCA 8112 or Lactococcus lactis subsp. lactis CIDCA 8221 also reduced the internalisation of S. flexneri into HT-29 cells although in a lesser extent than MM. Interestingly, Lactobacillus plantarum CIDCA 83114 exerted a protective effect on the invasion of Caco-2 and HT-29 cells by S. flexneri. Regarding the pro-inflammatory response on HT-29 cells, S. flexneri infection induced a significant activation of the expression of interleukin 8 (IL-8), chemokine (C-C motif) ligand 20 (CCL20) and tumour necrosis factor alpha (TNF- $\alpha$ ) encoding genes $(P<0.05)$, whereas incubation of cells with MM did not induce the expression of any of the mediators assessed. Interestingly, pre-incubation of HT-29 monolayer with MM produced an inhibition of S. flexneriinduced IL-8, CCL20 and TNF- $\alpha$ mRNA expression. In order to gain insight on the effect of MM (or the individual strains) on this pro-inflammatory response, a series of experiments using a HT-29-NF-kB-hrGFP reporter system were performed. Pre-incubation of HT-29-NF-kB-hrGFP cells with MM significantly dampened Shigella-induced activation. Our results showed that the contribution of yeast strain Kluyveromyces marxianus CIDCA 8154 seems to be crucial in the observed effect. In conclusion, results presented in this study demonstrate that pre-treatment with a microbial mixture containing bacteria and yeasts isolated from kefir, resulted in inhibition of S. flexneri internalisation into human intestinal epithelial cells, along with the inhibition of the signalling via NF- $\mathrm{kB}$ that in turn led to the attenuation of the inflammatory response.
\end{abstract}

Keywords: kefir microorganisms, Shigella flexneri, pro-inflammatory response

\section{Introduction}

Probiotics are classically defined as live microorganisms that administered in adequate amounts may confer health benefits to the host (FAO/WHO, 2002), and their use in food industry is increasing in the last decades. Numerous reports have demonstrated the ability of several species of lactobacilli, bifidobacteria and yeasts to exert beneficial effects, including protection of a potential host against infectious diseases caused by enteric pathogens and prevention of intestinal disorders (Gupta and Garg, 2009). Generally, these probiotic microorganisms are capable of inhibiting the action of pathogens, enhancing the intestinal barrier and modulating the immune response, among other effects (Plaza-Diaz et al., 2014; Servin, 2004). 
Kefir is a fermented product obtained by fermentation of milk with a complex microbiota confined to 'kefir grains', in which different lactic acid bacteria and yeasts coexist in a symbiotic association. Besides, kefir consumption has been associated with several health-promoting properties (Guzel-Seydim et al., 2011; Lopitz-Otsoa et al., 2006); different kefir-isolated microbial strains have also shown potentiality as probiotics (Santos et al., 2003; Zheng et al., 2013). In this sense, the ability of several bacterial and yeast strains isolated from kefir grains to inhibit different intestinal pathogenic bacteria such as Salmonella spp., Clostridium difficile, Shigella spp. and Escherichia coli have been demonstrated by in vitro and in vivo studies performed in our workgroup (Bolla et al., 2013a,b; Carasi et al., 2014; Golowczyc et al., 2007; Hugo et al., 2008; Kakisu et al., 2013; Trejo et al., 2010).

Shigella is a Gram-negative foodborne bacillus that is one of the most frequent causes of acute diarrhoea in developing countries (Kosek et al., 2010). Among different species, S. flexneri and Shigella sonnei are often isolated from children with bacillary dysentery (Merino et al., 2004; Xia et al., 2011). The pathogenesis of Shigella infection begins with an invasion of colonic and rectal epithelium followed by the intracellular bacterial replication and spread to adjacent cells (Watarai et al., 1995), thus causing an intense inflammatory response that triggers a dysenteric syndrome called shigellosis (Schroeder and Hilbi, 2008). In humans, analysis of cytokine expression in rectal biopsies of infected patients at the acute phase of the disease has revealed up-regulation of pro-inflammatory genes such as those encoding interleukin (IL)-1 $\beta$, IL-6, IL-8, tumour necrosis factor (TNF) $-\alpha$ and $-\beta$ (Phalipon and Sansonetti, 2007).

Some authors have reported that Lactobacillus strains are able to downregulate inflammatory responses elicited by S. flexneri (Tien et al., 2006) or enterohaemorragic E. coli (Stöber et al., 2010) on intestinal epithelial cell lines. In this context, the capability of different kefir-isolated strains of lactobacilli and yeasts belonging to CIDCA collection to modulate the flagellin-induced innate response on the Caco-2-ccl20:luc reporter system was recently reported (Carasi et al., 2015; Romanin et al., 2010).

We have previously reported that a microbial mixture containing three bacterial and two yeast strains isolated from kefir, inhibits the growth of S. sonnei in vitro (Bolla et al., 2011). More recently, this five-strain mixture demonstrated antagonism of the invasion of Hep-2 cells by S. flexneri and S. sonnei (Kakisu et al., 2013). Taking into account this background information, we aimed to evaluate the ability of this kefir-isolated microbial mixture to protect intestinal epithelial cells against S. flexneri invasion, as well as to analyse the effect on pro-inflammatory response elicited by this pathogen.

\section{Materials and methods}

\section{Microorganisms and culture conditions}

The microorganisms used in this study comprised Lactococcus lactis subsp. lactis CIDCA 8221, Lactobacillus plantarum CIDCA 83114, Lactobacillus kefiri CIDCA 8348, Kluyveromyces marxianus CIDCA 8154 and Saccharomyces cerevisiae CIDCA 8112, isolated from kefir grains and previously identified and characterised by Garrote et al. (2001), Delfederico et al. (2006) and Diosma et al. (2014). Also, a clinical isolate of $S$. flexneri strain 72, obtained from the Sor María Ludovica Interzonal Hospital (La Plata, Argentina), was used. Kefir-isolated microorganisms were cultured and propagated as described by Bolla et al. (2011).

\section{Preparation of the microbial mixture}

Each microorganism was cultured individually as described above. The microbial mixture (MM) was obtained as described by Bolla et al. (2011). The final concentrations of viable bacteria and yeasts in MM were $1 \times 10^{9} \mathrm{cfu} / \mathrm{ml}$ and $1 \times 10^{6} \mathrm{cfu} / \mathrm{ml}$, respectively. Viable counts were determined by plate counting using De Mann, Rogosa and Sharpe (MRS, Difco, Detroit, MI, USA) agar for lactobacilli, YGC (yeast extract glucose chloramphenicol agar; Biokard Diagnostic, Beauvais, France) for yeast strains, and 1.1.1. agar (Difco) for $L$. lactis. Plates were incubated at $30{ }^{\circ} \mathrm{C}$ for $24-48 \mathrm{~h}$ in aerobic conditions.

\section{Epithelial cell cultures}

Caco-2, and HT-29 cells were cultured in Dulbecco's Modified Eagle's Minimum Essential Medium (DMEM; Gibco BRL Life Technologies, Rockville, MD, USA) supplemented with $15 \%(\mathrm{v} / \mathrm{v})$ of foetal bovine serum (PAA Laboratories, GmbH, Pasching, Austria), 1\% (v/v) nonessential amino acids (Gibco BRL Life Technologies), and antibiotics (12 IU/ml penicillin and $12 \mathrm{mg} / \mathrm{ml}$ streptomycin; Gibco BRL Life Technologies).

HT-29 cells transfected with plasmid carrying a human recombinant green fluorescent protein reporter under the control of NF-kB promoter (HT-29-NF-kB-hrGFP; Tiscornia et al., 2012) were kindly provided by Dra. Mariela Bollati-Fogolín of Instituto Pasteur Montevideo. These cells were cultured in DMEM supplemented with $10 \%(\mathrm{v} / \mathrm{v})$ of foetal bovine serum, $1 \%(\mathrm{v} / \mathrm{v})$ non-essential amino acids and supplemented with 10\% v/v GlutaMAX (Gibco BRL Life Technologies).

Cells were inoculated $\left(2.5 \times 10^{5}\right.$ cells per well $)$ into 24 -well tissue-culture plates (Greiner Bio One, Frickenhausen, Germany) and incubated at $37{ }^{\circ} \mathrm{C}$ (14 days for Caco- 2 and $48 \mathrm{~h}$ for HT-29 cells) in a $5 \% \mathrm{CO}_{2}-95 \%$ air atmosphere. 


\section{Determination of Shigella flexneri invasion and effect of the microbial mixture}

The ability of $S$. flexneri strain 72 to invade human intestinal epithelial was assessed on Caco-2 and HT-29 cell lines. To perform control assays, monolayers were washed three times with sterile phosphate buffered saline (PBS; pH 7.2) and then $1 \times 10^{8} \mathrm{cfu} / \mathrm{ml}$ of $S$. flexneri in $500 \mu \mathrm{l}$ of serumfree DMEM were added to the cell culture and incubated for $1 \mathrm{~h}$ at $37^{\circ} \mathrm{C}$ in a $5 \% \mathrm{CO}_{2}-95 \%$ air atmosphere. The cell monolayers were washed with sterile PBS and then $1.0 \mathrm{ml}$ of gentamicin $(100 \mu \mathrm{g} / \mathrm{ml}$ in PBS) was added to each well and incubated for $1.5 \mathrm{~h}$ at $37^{\circ} \mathrm{C}$ in order to kill the bacteria that adhered to the surface. After incubation, the cells were washed again, and were lysed by addition of $1 \mathrm{ml}$ of sterile distilled water $\left(1 \mathrm{~h}\right.$ at $\left.37^{\circ} \mathrm{C}\right)$. Appropriate dilutions of cell lysates were plated in tryptic soy agar (Oxoid, Basingstoke, $\mathrm{UK}$ ) and incubated for $24 \mathrm{~h}$ at $37^{\circ} \mathrm{C}$ in order to determine the number of internalised S. flexneri.

For the assessment of the protective effect of MM or the individual strains, cell monolayers were pre-incubated with $500 \mu \mathrm{l} \mathrm{MM}$ or individual strains $\left(1 \times 10^{9} \mathrm{cfu} / \mathrm{ml}\right.$ for bacteria and $1 \times 10^{6} \mathrm{cfu} / \mathrm{ml}$ for yeast) for $1 \mathrm{~h}$, before addition of S. flexneri. Some experiments in presence of DMEM supernatant previously incubated with $\mathrm{MM}$ for $1 \mathrm{~h}$ at $37^{\circ} \mathrm{C}$ (MM-DMEM supernatant) were also performed.

\section{Modulation of innate immune response on HT-29 cells}

Confluent cultures of HT-29 cells were incubated with MM or individual strains and then infected with $1 \times 10^{8} \mathrm{cfu} / \mathrm{ml}$ of $S$. flexneri in serum-free DMEM and then incubated for $1 \mathrm{~h}$ at $37{ }^{\circ} \mathrm{C}$ in a $5 \% \mathrm{CO}_{2}-95 \%$ air atmosphere. After incubation, samples were homogenised in RA1 lysis buffer (GE Healthcare, Munich, Germany) to perform the extraction of total RNA. Non-infected controls and controls without microbial pre-incubation were performed. Also, cells stimulated with TNF- $\alpha$ (3 ng/ml) (Sigma-Aldrich, St. Louis, MO, USA) were used as positive control of activation.

\section{Quantification of gene expression in HT-29 cells by qRT- PCR}

\section{RNA extraction and CDNA synthesis}

Total RNA was isolated using the Illustra RNAspin Mini kit (GE Healthcare, Wauwatosa, WI USA) following the manufacturer's instructions. $100 \mathrm{ng}$ of total RNA was reversed transcribed using $M-M L V$ reverse transcriptase (Promega, Madison, WI, USA).

\section{Quantitative PCR}

Quantitative real-time PCR analyses were performed using an iCycler (Bio-Rad, Hercules, CA, USA) according to the following protocol: $2 \mathrm{~min}$ at $50{ }^{\circ} \mathrm{C}$ and $10 \mathrm{~min}$ at $95{ }^{\circ} \mathrm{C}$, followed by 40 cycles of amplification with $1 \mathrm{~min}$ annealing/ extension at $60{ }^{\circ} \mathrm{C}$ and denaturation at $95^{\circ} \mathrm{C}$ for $15 \mathrm{~s}$. The reaction mixture comprised Super iQ SYBR Green PCR Mix (Bio-Rad), $0.5 \mu \mathrm{mol} / \mathrm{l}$ of each primer, and the respective standardised cDNA as a template. Primers for chemokine (C-C motif) ligand 20 (CCL20), IL-8, TNF- $\alpha$, IL-6 or human actin (housekeeping gene), and relative difference calculation using the $\Delta \mathrm{Ct}$ method were previously described (Anderle et al., 2005; Rumbo et al., 2004). The results were expressed respect to the basal expression of HT-29 control cells.

\section{Activation of HT-29-NF-KB-hrGFP reporter system}

Confluent cultures HT-29-NF-кB-hrGFP cells were incubated with $\mathrm{MM}$ or individual strains for $1 \mathrm{~h}$ at $37^{\circ} \mathrm{C}$ in a $5 \% \mathrm{CO}_{2}-95 \%$ air atmosphere. The cell monolayer was washed for three times with sterile PBS, and $1 \times 10^{8}$ $\mathrm{cfu} / \mathrm{ml}$ of $S$. flexneri in $500 \mu \mathrm{l}$ of serum-free DMEM were added to the cell culture, and incubated for $1 \mathrm{~h}$ at the same environmental conditions. After that, $1.0 \mathrm{ml}$ of gentamicine $(100 \mu \mathrm{g} / \mathrm{ml}$ in PBS) was added to each well and plates were incubated by $18 \mathrm{~h}$ at $37^{\circ} \mathrm{C}$ in controlled atmosphere. Upon incubation, cells were washed three times with sterile PBS, and then harvested by trypsinisation (Gibco BRL Life Technologies). Percentage of GFP-positive cells was determined by flow cytometry using a FACSCalibur ${ }^{\mathrm{rax}}$ cell analyser (BD Bioscience, Franklin Lakes, NJ, USA). Non-infected controls and controls without microbial pre-incubation were included. Also, cells stimulated with TNF- $\alpha$ (3 ng/ml) (Sigma-Aldrich) were used as positive control of activation.

\section{Statistical analysis}

Data analysis was performed using GraphPad Prism version 5.00 for Windows (GraphPad Software, San Diego, CA, USA). The results were statistically tested using a Student t-test to determine any significant difference $(P<0.05)$.

\section{Results}

\section{Effect of pre-incubation with kefir-isolated microorganisms on invasion of cultured cells by Shigella flexneri}

In order to evaluate the effect of microbial pre-incubation on Shigella invasion, in vitro assays using two different intestinal epithelial cell lines (Caco-2 and HT-29) were performed. A significant decrease in S. flexneri strain 72 invasion was observed on HT-29 cells pre-incubated with MM (Figure 1A). Pre-incubation with the individual strains 

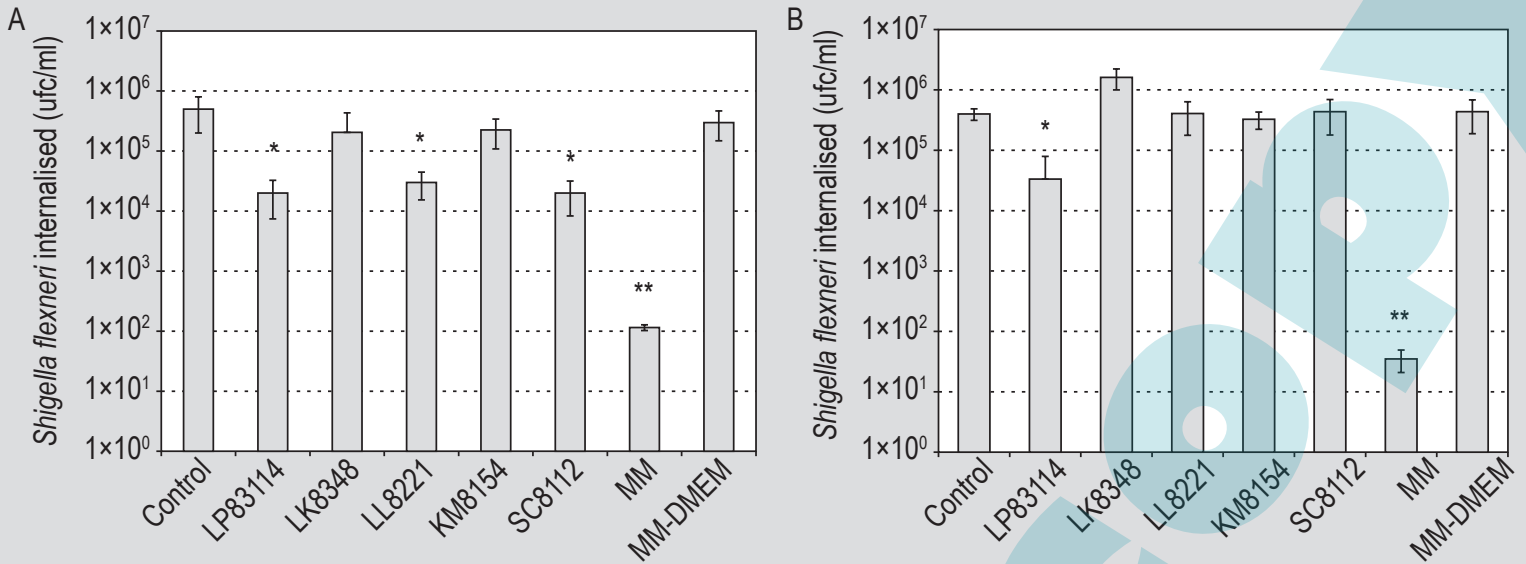

Figure 1. Effect of microbial mixture (MM) or isolated microorganisms pre-incubation on Shigella flexneri 72 strain invasion in (A) HT-29 and (B) Caco-2 cultured cells. Control: S. flexneri infected control cells; LP83114: pre-incubation with Lactobacillus plantarum CIDCA 83114; LK8348: pre-incubation with Lactobacillus kefiri CIDCA 8348; LL8221: pre-incubation with Lactococcus lactis CIDCA 8221; KM8154: pre-incubation with Kluyveromyces marxianus CIDCA 8154; SC8112: pre-incubation with Saccharomyces cerevisiae CIDCA 8112; MM: pre-incubation with MM; MM-DMEM: pre-incubation with MM-DMEM supernatant. Results are expressed as means \pm standard deviation. ${ }^{* *} P<0.05$ vs other pre-incubation treatments; ${ }^{*} P<0.05$ vs Shigella-infected control cells.

S. cerevisiae CIDCA 8112, L. plantarum CIDCA 83114 or L. lactis subsp. lactis CIDCA 8221 also reduced the internalisation of $S$. flexneri into HT-29 cells although in a lesser extent than MM. No effects were observed with L. kefiri CIDCA 8348 and K. marxianus CIDCA 8154 (Figure 1A).

Assays on Caco- 2 cells showed that the number of S. flexneri strain 72 internalised after pre-incubation of enterocytelike cells with MM significantly decreased as compared to control infected cells (around 4 log units) (Figure 1B). Interestingly, L. plantarum CIDCA 83114 also exerted a protective effect on the invasion of Caco- 2 cells by $S$. flexneri, but the other strains under study failed to protect cells from invasion (Figure 1B). It is worth to note that pre-incubation of Caco-2 or HT-29 cells with MM-DMEM supernatant did not affect $S$. flexneri invasion on these intestinal epithelial cell lines (Figure 1).

\section{Modulation of pro-inflammatory response on HT-29 cells.}

Since S. flexneri infection of human intestinal epithelial cells initiates an inflammatory process characterised by the induction of different cytokines and chemokines (Pédron et al., 2003), we analysed the effect of pre-incubation with MM on the expression of genes encoding TNF- $\alpha$, IL-8 and CCL20 in S. flexneri infected-HT-29 cells. As it shown in Figure 2, S. flexneri infection induced a significant activation of the expression of $i l-8, c c l 20$ and $t n f-\alpha$ in these cells $(P<0.05)$, whereas incubation with MM did not induce the expression of any of the mediators assessed. Interestingly, pre-incubation of HT-29 monolayer with MM produced an inhibition of S. flexneri-induced IL-8 (47-fold), CCL20 (68-fold) and TNF- $\alpha$ (7.8-fold) mRNA expression.

\section{Modulation of Shigella flexneri-induced activation of HT- 29-NF-KB-hrGFP reporter system}

It has been demonstrated that gene transcription of several markers of acute inflammation induced by $S$. flexneri infection of epithelial cells, is related to the NF- $\mathrm{kB}$ pathway (Philpott et al., 2000). In order to gain insight on the effect of MM or the individual strains on pro-inflammatory response of intestinal epithelial cells induced by $S$. flexneri infection, a series of experiments using HT-29-NF-KB-hrGFP cells were performed.

Infection with S. flexneri strain 72 induced a significant activation of the reporter gene (hrGFP) in the $14 \%$ of the total cells (Figure 3). This value is significantly higher than that of control unstimulated cells (around 2\%). The positive control (TNF- $\alpha$ stimulated cells) showed values of 30\% positive cells (data not shown). Pre-incubation of HT-29NF-кB-hrGFP cells with MM dampened Shigella-induced activation leading to values of less than $2 \%$ positive cells (Figure 3). No activation was found in cells stimulated only with MM. Interestingly, K. marxianus CIDCA 8154 also interfered with the activation due to S. flexneri, when it was present as the sole probiotic strain. The other strains under study also inhibited activation when they were used as single strains, but in a significant lesser extent than $K$. marxianus CIDCA 8154. 


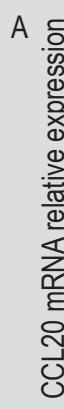

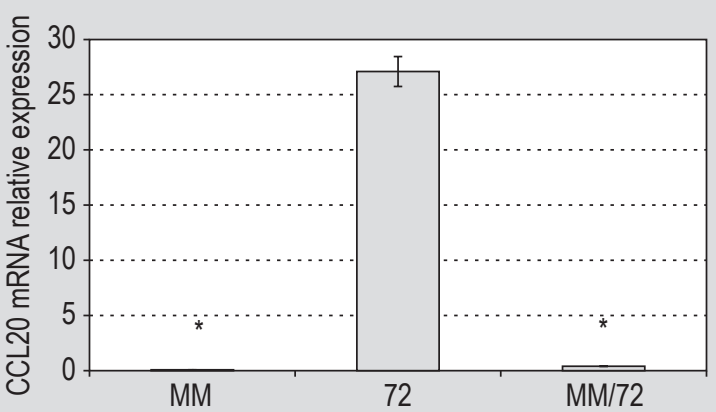

B

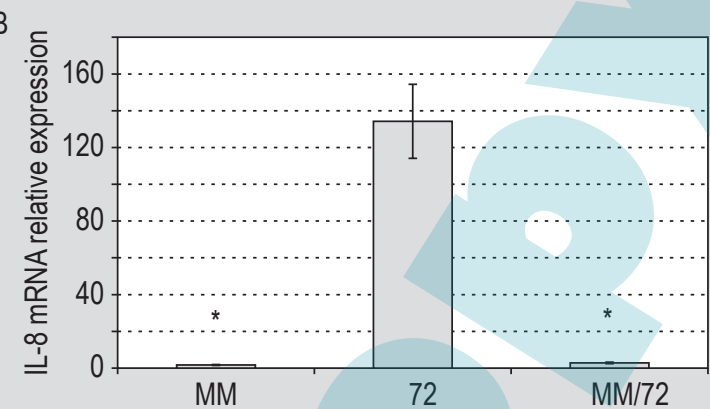

C

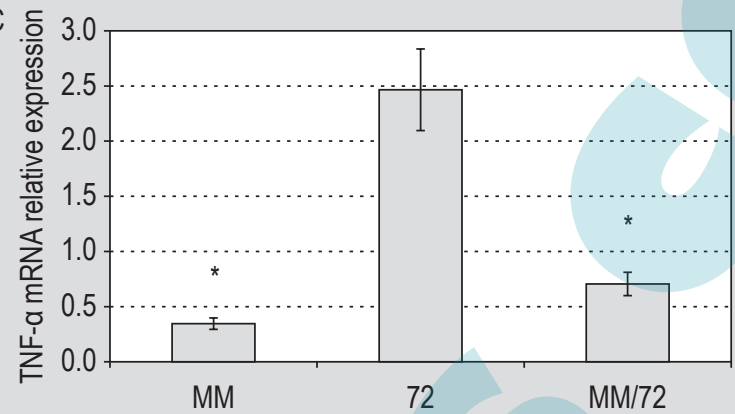

Figure 2. Relative expression of genes encoding (A) chemokine (C-C motif) ligand 20 (CCL20), (B) interleukin 8 (IL-8) and (C) tumour necrosis factor alpha (TNF- $\alpha$ ) in HT-29 cells. 72: after infection with Shigella flexneri strain 72; MM/72: pre-incubation with microbial mixture (MM) and Shigella infection; MM: incubation with MM. Results are expressed as mean \pm standard deviation and representative of at least two independent experiments. Human $\beta$-actin was used to normalise gene expression. * $P<0.05$ vs Shigella-infected control cells.

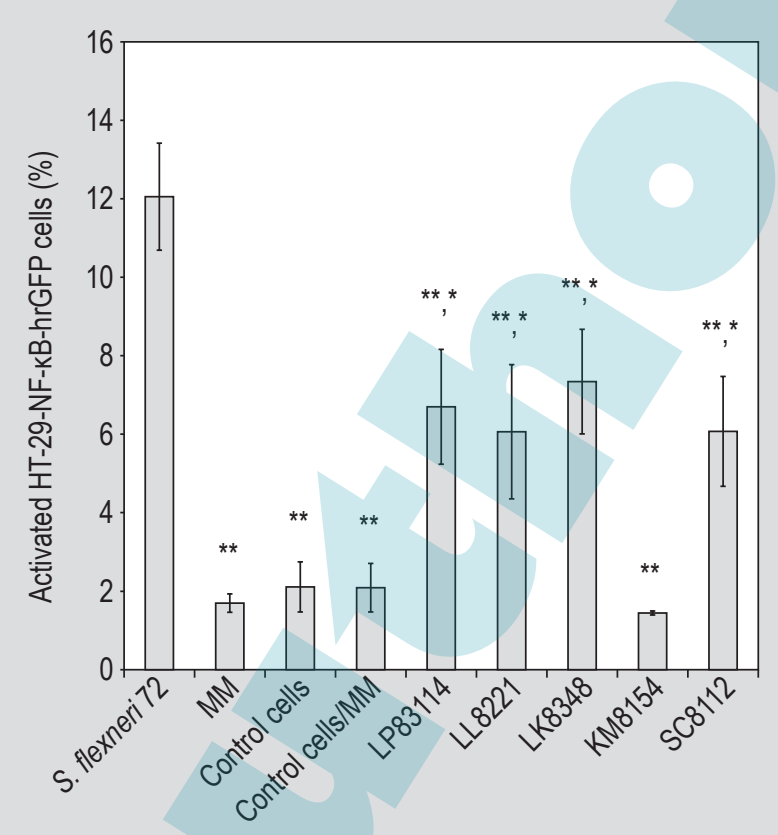

Figure 3. Percentage of activated HT29-NF-kB-hrGFP cells by Shigella flexneri 72 in presence or not of microbial mixture (MM) or single strains. Results are expressed as mean \pm standard deviation. * $P<0.05$ vs MM pre-incubation treatment; ${ }^{* *} P<0.05$ vs Shigella-infected cells.

\section{Discussion}

In this study, we have investigated the protective effect of MM, consisting of three bacteria and two yeasts isolated from kefir, against S. flexneri invasion of human intestinal epithelial cells, as well as on the effect on pro-inflammatory response elicited by this bacterial pathogen. Although this five-strain mixture was shown to inhibit the growth of $S$. sonnei in vitro (Bolla et al., 2011) as well as to antagonise the invasion of mammalian Hep-2 cells by S. sonnei and S. flexneri (Kakisu et al., 2013), no studies regarding its ability to protect intestinal epithelial cells against Shigella infection have been previously reported.

Since the gut epithelium represents the first physical barrier against Shigella and other enteropathogens, the ability of probiotic microorganisms to avoid the bacterial invasion of intestinal epithelial cells, is one of the critical steps of their protective action. In this sense, several authors have shown that some strains of lactobacilli are able to inhibit the adhesion and invasion of Shigella on intestinal epithelial cell lines (Moorthy et al., 2010; Zhang et al., 2012). Our results show that the number of $S$. flexneri internalised by the intestinal epithelial cell lines Caco-2 and HT-29 significantly decreased when cells were pre-incubated with MM, which are in agreement with a similar protective effect on Hep-2 cells (Kakisu et al., 2013). 
However, when the effect of isolated strains was assessed, some differences were observed between both cell lines. Particularly, although L. plantarum CIDCA 83114 was able to antagonise Shigella invasion on both Caco-2 and HT-29 cells, L. lactis CIDCA 8221 and S. cerevisiae CIDCA 8112 showed only a protective effect in the model with HT-29 cells. These findings could be attributed to differences between both experimental models of human intestinal epithelium. Additionally, the inhibitory power of MM is significantly higher than that exerted by each isolated microorganism alone, suggesting a synergistic effect of MM. Similar results were reported by Moorthy et al. (2010) who observed that a combination of L. rhamnosus and $L$. acidophilus offered a better protection during Shigella dysenteriae infection as compared with single strains.

Taking into account that soluble metabolites could mediate the inhibition of pathogen invasion, DMEM supernatant obtained after incubation with MM for $1 \mathrm{~h}$ (the same time that cells were pre-incubated with kefir-microorganisms) was tested, and no effect was observed on S. flexneri internalisation. This suggests that the observed effects are due to direct microbe-enterocyte interaction. In this context, a competition between kefir microorganisms and S. flexneri for adhesion sites on intestinal epithelial cells cannot be excluded, in particular in the case of the inhibitory effect exerted by L. plantarum. Further research will be needed in order to test this hypothesis. On the other hand, Shigella-exclusion due to agglutination with yeast cells can be ruled out since no agglutination was observed in any of our previous studies with these microorganisms (Bolla et al., 2011; Kakisu et al., 2013).

It is known that enteroinvasive bacteria stimulate mucosal inflammation that results in severe tissue destruction. Epithelial invasion by Shigella and spreading to the basolateral domain lead to massive recruitment of neutrophils that contributes to the rupture of the epithelial barrier thus facilitating bacterial invasion (Pédron et al., 2003). This process is accompanied by secretion of different cytokines and chemokines by intestinal cells that in turn initiate the inflammatory process.

In the present study, the expression of IL-8, a proinflammatory chemokine produced by epithelial cells in response to contact between a variety of invasive microorganisms and the epithelial basolateral membrane (Eckmann et al., 2000; Köhler et al., 2002), was significantly increased in HT-29 infected with S. flexneri strain 72. An increment was also observed in these cells for the TNF- $\alpha$ encoding gene, a cytokine that plays a major role in epithelial destruction in experimental shigellosis (D'Hauteville et al., 2002). The activation of expression of these two potent mediators was previously reported for HT-29 cells infected with S. dysenteriae (Jung et al., 1995; Moorthy et al., 2010) and other invasive bacteria such as Salmonella
Dublin, Yersinia enterocolitica and enteroinvasive E. coli (Jung et al., 1995). Furthermore, infection with S. flexneri strain 72 induced the up-regulation of CCL20, a potent chemoattractant for dendritic cells, suggesting a potential of this strain for the recruitment of these cells which have an instrumental role in the induction of the adaptive immune response in the gut (Sierro et al., 2001). In concordance with our results, other authors observed a similar activation of IL-8, CCL20 and TNF- $\alpha$ encoding genes after infection of human Caco-2 cells with an invasive strain of $S$. flexneri (Pédron et al., 2003).

Interestingly, pre-incubation of HT-29 cells with MM produced a strong inhibition of the Shigella-induced activation of IL-8, CCL20 and TNF- $\alpha$ gene's expression. Noteworthy, Tien et al. (2006) observed that L. casei down-regulate the transcription of a number of genes encoding pro-inflammatory effectors such as cytokines and chemokines and adherence molecules induced by invasive phenotype of $S$. flexneri in Caco-2 cells. Similarly, L. rhamnosus and L. acidophilus synergistically inhibit the pro-inflammatory response elicited by $S$. dysenteriae infection in Caco-2 cells (Moorthy et al., 2010). However, the mechanism of protection and the relationship with the suppression of inflammation has not been established. According to the sequence of the events leading to the observed results, we can foresee two scenarios: the treatment with MM diminish inflammation thus leading to a decrease in Shigella internalisation or the diminution of Shigella internalisation triggers an anti-inflammatory effect. Certainly these issues deserve future research.

As far as we know, our work constitutes the first report showing the ability of a mixture of bacteria and yeasts to down-regulate the Shigella-induced pro-inflammatory response on intestinal epithelial cells. Our results demonstrated that both bacterial and yeast strains included in the MM are able to modify key events of the interaction between Shigella and eukaryotic cells. These findings are in agreement with a previous report by Romanin et al. (2010) who demonstrated that S. cerevisiae CIDCA 8112, K. marxianus CIDCA 8154 and other yeast strains isolated from kefir showed a high capacity to inhibit intestinal epithelial innate response triggered by different pro-inflammatory stimuli, such as flagellin, $E$. coli lipopolysaccharides or IL- $1 \beta$.

It is known that nuclear factor (NF)- $\mathrm{B}$ is a central regulator in the activation of numerous genes involved in pro-inflammatory responses, and diverse cell functions such as growth, differentiation, adhesion and apoptosis (Jobin and Sartor, 2000). The NF-kB pathway mediates the transcription of several genes related to acute inflammation, such as IL-8 and CCL20 which are activated in S. flexneriinfected epithelial cells (Philpott et al., 2000; Tien et al., 2006). By using a reporter system under the control of a 
NF $-\kappa B$ promoter, we observed that either MM or isolated strains are able to modulate the Shigella-induced activation of the NF-kB pathway, suggesting that the inhibition of proinflammatory response is related to this signalling pathway. However, the contribution of yeast strain $K$. marxianus CIDCA 8154 seems to be crucial in the observed effect. In this sense, using several reporter systems and different stimuli, other authors have reported the inhibition of the NF-kB pathway by co-incubation with individual lactic acid bacteria (Stober et al., 2010; Tien et al., 2006) or yeasts (Romanin et al., 2010; Sougioultzis et al., 2006), but no results regarding mixtures of potentially probiotic microorganisms have been reported.

According to our results, although each microorganism is able to modulate NF-kB activation, the inhibitory power of $\mathrm{MM}$ is significantly higher than those of individual strains. These findings support the idea, as well as described above for the inhibition of Shigella internalisation, that microorganisms could act synergistically in order to protect intestinal epithelial cells from damage caused by infection.

In conclusion, results presented in this study demonstrate that pre-treatment with a microbial mixture containing bacteria and yeasts isolated from kefir, resulted in inhibition of $S$. flexneri internalisation into human intestinal epithelial cells, along with the inhibition of the signalling via NF- $\mathrm{BB}$ that in turn led to the attenuation of the inflammatory response.

\section{Acknowledgements}

This work was supported by Agencia Nacional de Promoción Científica y Tecnológica (PICT 2013-1205, PICT 2012-0910), CONICET (PIP 0511, PIP 0577) and Universidad Nacional de La Plata (Projects 11X/686, 11X/670). P.A. Bolla, A.G. Abraham, P.F. Pérez and M.A. Serradell are researchers of the Consejo Nacional de Investigación Científica y Tecnológica (CONICET).

\section{References}

Anderle, P., Rumbo, M., Sierro, F., Mansourian, R., Michetti, P., Roberts, M.A. and Kraehenbuhl, J.P., 2005. Novel markers of the human follicle-associated epithelium identified by genomic profiling and microdissection. Gastroenterology 129: 321-327.

Bolla, P.A., Carasi, P., De Los Angeles Serradell, M. and De Antoni, G.L., 2013a. Kefir-isolated Lactococcus lactis subsp. lactis inhibits the cytotoxic effect of Clostridium difficile in vitro. Journal of Dairy Research 80: 96-102.

Bolla, P.A., Carasi, P., De Los Angeles Bolla, M., De Antoni, G.L. and De Los Angeles Serradell, M., 2013b. Protective effect of a mixture of kefir-isolated lactic acid bacteria and yeasts in a hamster model of Clostridium difficile infection. Anaerobe 21: 28-33.
Bolla, P.A., De Los Angeles Serradell, M., De Urraza, P.J. and De Antoni, G.L., 2011. Effect of freeze-drying on viability and in vitro probiotic properties of a mixture of lactic acid bacteria and yeasts isolated from kefir. Journal of Dairy Research 78: 15-22.

Carasi, P., Diaz, M., Racedo, S.M., De Antoni, G.L., Urdaci, M.C. and de Los Angeles Serradell M., 2014. Safety characterization and antimicrobial properties of kefir-isolated Lactobacillus kefiri. BioMed Research International 2014: 208974.

Carasi, P., Racedo, S.M., Jacquot, C., Romanin, D.E., De Los Angeles Serradell, M. and Urdaci, M.C., 2015. Impact of kefir derived Lactobacillus kefiri on the mucosal immune response and gut microbiota. Journal of Immunology Research 2015: 361604

Delfederico, L., Hollmann, A., Martínez, M., Iglesias, N.G., De Antoni, G.L. and Semorile L., 2006. Molecular identification and typing of lactobacilli isolated from kefir grains. Journal of Dairy Research 73: 20-27.

D’Hauteville, H., Khan, S., Maskell, D.J., Kussak, A., Weintraub, A., Mathison, J., Ulevitch, R.J., Wuscher, N., Parsot, C. and Sansonetti, P.J., 2002. Two msbB genes encoding maximal acylation of lipid A are required for invasive Shigella flexneri to mediate inflammatory rupture and destruction of the intestinal epithelium. Journal of Immunology 168: 5240-5251.

Diosma, G., Romanin, D.E., Rey-Burusco, M.F., Londero, A. and Garrote, G.L., 2014. Yeasts from kefir grains: isolation, identification, and probiotic characterization. World Journal of Microbiology and Biotechnology 30: 43-53.

Eckmann, L., Smith, J.R., Housley, M.P., Dwinell, M.B. and Kagnoff, M.F., 2000. Analysis by high density cDNA arrays of altered gene expression in human intestinal epithelial cells in response to infection with the invasive enteric bacteria Salmonella. Journal of Biological Chemistry 275: 14084-14094.

Food and Agriculture Organization of the United Nations/World Health Organization (FAO/WHO), 2002. Guidelines for the evaluation of probiotics in food. Report of a Joint FAO/WHO working group on drafting guidelines for the evaluation of probiotics in food. Available at: http://tinyurl.com/ou88oa2.

Garrote, G.L., Abraham, A.G. and De Antoni, G.L., 2001. Chemical and microbiological characterisation of kefir grains. Journal of Dairy Research 68: 639-652.

Golowczyc, M., Mobili, P., Garrote, G.L., Abraham, A.G. and De Antoni, G.L., 2007. Protective action of Lactobacillus kefir carrying S-layer protein against Salmonella enterica serovar Enteritidis. International Journal of Food Microbiology 118: 264-273.

Gupta, V. and Garg, R., 2009. Probiotics. Indian Journal of Medical Microbiology 27: 202-209.

Guzel-Seydim, Z.B., Kok-Tas, T., Greene, A.K. and Seydim, A.C., 2011. Functional properties of kefir. Critical Reviews of Food and Science Nutrition 51: 261-268.

Hugo, A.A., Kakisu, E., De Antoni, G.L. and Pérez, P.F., 2008. Lactobacilli antagonize biological effects of enterohaemorrhagic Escherichia coli in vitro. Letters in Applied Microbiology 46: 613-619.

Jobin, C. and Sartor, R.B., 2000. IkB/NF-kB system: a key determinant of mucosal inflammation and protection. American Journal of Physiology: Cell Physiology 278: C451-C462. 
Jung, H.C., Eckmann, L., Yang, S.K., Panja, A., Fierer, J., MorzyckaWroblewska, E. and Kagnoff, M.F., 1995. A distinct array of proinflammatory cytokines is expressed in human colon epithelial cells in response to bacterial invasion. Journal of Clinical Investigation 95: 55-65.

Kakisu, E., Bolla, P.A., Abraham, A.G., De Urraza, P. and De Antoni, G.L., 2013. Lactobacillus plantarum isolated from kefir: protection of cultured Hep-2 cells against Shigella invasion. International Dairy Journal 33: 22-26.

Köhler, H., Rodrigues, S.P. and McCormick, B.A., 2002. Shigella flexneri interactions with the basolateral membrane domain of polarized model of intestinal epithelium: role of lipopolysaccharide in cell invasion and inactivation of the mitogen-activated protein kinase ERK. Infection and Immunity 70: 1150-1158.

Kosek, M., Yori, P.P. and Olortegui, M.P., 2010. Shigellosis update: advancing antibiotic resistance, investment empowered vaccine development, and green bananas. Current Opinion in Infectious Diseases 23: 475-480.

Lopitz-Otsoa, F., Rementeria, A., Elguezabal, N. and Garaizar, J., 2006. Kefir: a symbiotic yeasts-bacteria community with alleged healthy capabilities. Revista Iberoamericana de Micología 23: 67-74.

Merino, L.A., Hreñuk, G.E., Ronconi, M.C. and Alonso, J.M., 2004. Resistencia a antibióticos y epidemiología molecular de Shigella spp. en el nordeste argentino. Revista Panamericana de Salud Pública 15: 219-224.

Moorthy, G., Murali, M.R. and Niranjali Devaraj, S., 2010. Lactobacilli inhibit Shigella dysenteriae 1 induced pro-inflammatory response and cytotoxicity in host cells via impediment of Shigella-host interactions. Digestive and Liver Disease 42: 33-39.

Pédron, T., Thibault, C. and Sansonetti, P.J., 2003. The invasive phenotype of Shigella flexneri directs a distinct gene expression pattern in the human intestinal epithelial cell line Caco-2. Journal of Biological Chemistry 278: 33878-33886.

Phalipon, A. and Sansonetti, P.J., 2007. Shigella's ways of manipulating the host intestinal innate and adaptative immune system: a tool box for survival? Immunology and Cell Biology 85: 119-129.

Philpott, D.J., Yamaoka, S., Israel, A. and Sansonetti, P.J., 2000. Invasive Shigella flexneri activates NF-кB through a lipopolysaccharidedependent innate intracellular response and leads to IL-8 expression in epithelial cells. Journal of Immunology 165: 903-914.

Plaza-Diaz, J., Gomez-Llorente, C., Fontana, L. and Gil, A., 2014. Modulation of immunity and inflammatory gene expression in the gut, in inflammatory diseases of the gut and in the liver by probiotics. World Journal of Gastroenterology 20: 15632-15649.

Romanin, D., Serradell, M., González Maciel, D., Lausada, N., Garrote, G.L. and Rumbo, M., 2010. Down-regulation of intestinal epithelial innate response by probiotic yeasts isolated from kefir. International Journal of Food Microbiology 140: 102-108.

Rumbo, M., Sierro, F., Debard, N., Kraehenbuhl, J.P. and Finke, D., 2004. Lymphotoxin beta receptor signaling induces the chemokine CCL20 in intestinal epithelium. Gastroenterology 127: 213-223.
Santos, A., San Mauro, M., Sánchez, A., Torres, J.M. and Marquina, D., 2003. The antimicrobial properties of different strains of Lactobacillus spp. isolated from kefir. Systematic and Applied Microbiology 26: 434-437.

Schroeder, G.N. and Hilbi, H., 2008. Molecular pathogenesis of Shigella spp.: controlling host cell signalling, invasion and death by type III secretion. Clinical Microbiology Reviews 21: 134-156.

Servin, A.L., 2004. Antagonistic activities of lactobacilli and bifidobacteria against microbial pathogens. FEMS Microbiology Reviews 28: 405-440.

Sierro, F., Dubois, B., Coste, A., Kaiserlian, D., Kraehenbuhl, J.P. and Sirard, J.C., 2001. Flagellin stimulation of intestinal epithelial cells triggers CCL20-mediated migration of dendritic cells. Proceedings of National Academy of Sciences of the USA 98: 13722-13727.

Sougioultzis, S., Simeonidis, S., Bhaskar, K.R., Chen, X., Anton, P.M., Keates, S., Pothoulakis, C. and Kelly, C.P., 2006. Saccharomyces boulardii produces a soluble anti-inflammatory factor that inhibits NF- $\mathrm{kB}-$ mediated IL-8 gene expression. Biochemical and Biophysical Research Communications 343: 69-76.

Stöber, H., Maier, E. and Schmidt, H., 2010. Protective effects of Lactobacillus, bifidobacteria and staphylococci on the infection of cultures HT29 cells with different enterohemorragic Escherichia coli serotypes are strain-specific. International Journal of Food Microbiology 144: 133-140.

Tien, M.T., Girardin, S.E., Regnault, B., Le Bourhis, L., Dillies, M.A., Coppée, J.Y., Bourdet-Sicard, R., Sansonetti, P.J. and Pédron, T., 2006. Anti-inflammatory effect of Lactobacillus casei on Shigellainfected human intestinal epithelial cells. Journal of Immunology 176: $1228-1237$.

Tiscornia, I., Hernández, A. and Bollati-Fogolín, M., 2012. Human monocyte-derived dendritic cells from leukoreduction system chambers after platelet pheresis are functional in an in vitro coculture assay with intestinal epithelial cells. Journal of Immunological Methods 384: 164-170.

Trejo, F.M., Pérez, P.F. and De Antoni, G.L., 2010. Co-culture with potentially probiotic microorganisms antagonises virulence factors of Clostridium difficile in vitro. Antonie Van Leeuwenhoek 98: 19-29.

Watarai, M., Tobe, T., Yoshikawa, M. and Sasakawa, C., 1995. Contact of Shigella with host cells triggers release of Ipa invasins and is an essential function of invasiveness. EMBO Journal 14: 2461-2470.

Xia, S., Xu, B., Huang, L., Zhao, J. Y., Ran, L., Zhang, J., Chen, H., Pulsrikarn, C., Pornruangwong, S., Aarestrup, F. and Hendriksen, R.S., 2011. Prevalence and characterization of human Shigella infections in Henan Province, China, in 2006. Journal of Clinical Microbiology 49: 232-242.

Zheng, Y., Lu, Y., Wang, J., Yang, L., Pan, C. and Huang, Y., 2013. Probiotic properties of Lactobacillus strains isolated from Tibetan kefir grains. PLoS ONE 8: e69868.

Zhang, Y-C., Zhang, L-W., Mab, W., Yi, H-X., Yang, X., Du, M., Shan, Y-J., Han, X. and Zhang, L-L., 2012. Screening of probiotic lactobacilli for inhibition of Shigella sonnei and the macromolecules involved in inhibition. Anaerobe 18: 498-503. 